\title{
La tutela individual de los derechos sociales por parte de la Corte Constitucional de Colombia a partir de las críticas al Supremo Tribunal Federal de Brasil
}

\author{
The Individual Protection of Social Rights by the Constitutional Court of \\ Colombia based on the Criticism of the Supreme Federal Court of Brazil
}

William Iván GALLO APONTE 1

\begin{abstract}
Resumen: La protección judicial de derechos sociales basadas únicamente en su dimensión subjetiva, por parte de la Corte Constitucional de Colombia, viene siendo analizada de manera inadecuada, pues desconoce la existencia de una doble faceta (individual y transindividual) y una multidimensionalidad de estos derechos. Frente a lo anterior, el trabajo concluye que, el análisis actual de la concesión de prestaciones individuales presenta inconsistencias que se pueden percibir en las críticas realizadas a las decisiones del Supremo Tribunal Federal de Brasil, fundadas en la teoría de los derechos fundamentales sociales como un todo. Asimismo, esas inconsistencias representan un comportamiento judicial riesgoso en ambos tribunales, por lo que es importante evaluar la hermenéutica constitucional, identificando límites que permitan garantizar, principalmente, la reducción colectiva de las desigualdades sociales.
\end{abstract}

Palabras clave: Derechos fundamentales como un todo, Desigualdad social, Activismo judicial, Supremo Tribunal Federal de Brasil, Corte Constitucional de Colombia

Abstract: The judicial protection of social rights based solely on their subjective dimension by the Colombian Constitutional Court has been analyzed in an inadequate manner since it ignores the existence of a double facet (individual and trans individual) and multidimensionality of these rights. In view of the above, the paper concludes that the current analysis of the granting of individual benefits presents inconsistencies that can be perceived in the criticisms made of the decisions of the Brazilian Federal Supreme Court, founded on the theory of social fundamental rights as a whole. Also, these inconsistencies represent a risky judicial behavior in both courts,

\footnotetext{
${ }^{1}$ Doctorando y Maestro en Derecho Económico y Desarrollo por la Pontifícia Universidade Católica do Paraná - PUCPR, Brasil. Investigador del "Núcleo de Pesquisas em Políticas Públicas e Desenvolvimento humano - NUPED" de la PUCPR y de la Universidad Externado de Colombia. Abogado por la Universidad Externado de Colombia. Correo electrónico: williamg.aponte@gmail.com
} 
so it is important to evaluate the constitutional hermeneutics, identifying limits that allow guaranteeing, mainly, the collective reduction of social inequalities.

Keywords: Fundamental Rights as a whole, Social Inequality, Judicial activism, Federal Supreme Court of Brazil, Constitutional Court of Colombia

\section{Introducción}

En un contexto marcado por una proliferación de acciones judiciales, una falta de logística judicial y un alto grado de incumplimiento de sentencias proferidas por los tribunales constitucionales en general, y por la Corte Constitucional, en particular, ${ }^{2}$ los derechos sociales cobran un protagonismo importante.

Considerándose la relación que impone, por un lado, el elevado número de incumplimientos de las órdenes de tutela, y por otro, la creciente cifra de demandas radicadas ante la Corte Constitucional, el presente escrito tiene por objetivo analizar los riesgos derivados de la tutela individual de los derechos sociales en la jurisprudencia de la Corte Constitucional. Sobre ese objetivo, se pretende confirmar la hipótesis según la cual, la protección judicial de los derechos sociales por la Corte Constitucional de Colombia viene siendo analizada de forma errónea, tanto por la jurisprudencia, como por la doctrina, por cuanto alega prevalentemente sólo una dimensión subjetiva de los mismos, dejando de lado la existencia de una doble faceta (individual y transindividual) y una multidimensionalidad de estos.

Desde el punto de vista metodológico, fueron utilizados los métodos deductivo, comparado y empírico. Con relación al primero, se compone de una revisión bibliográfica de la doctrina que desarrolla la teoría de los derechos sociales. En segundo lugar, en lo que tiene que ver con el método de derecho comparado, se da paso al análisis crítico de la doctrina brasilera con relación a las decisiones del Supremo Tribunal Federal; críticas fundadas en la teoría de los derechos fundamentales como un todo, su multifuncionalidad y su doble titularidad.

Finalmente, se utiliza un método de investigación empírica, que atiende a una relectura de la jurisprudencia de la Corte Constitucional, de manera prevalente a partir del 2007, año a partir del cual se reconocen los derechos sociales como verdaderos derechos fundamentales. A pesar de esta prevalencia, se hará referencia a algunas decisiones anteriores con el objetivo de dar

${ }^{2}$ Corporación Excelencia de la Justicia (2020). A título de ejemplo, tan solo para el 2019, el 60\% de las tutelas falladas en salud, así como el $47 \%$ sobre el derecho al mínimo vital, fueron desacatadas. 
contexto a las discusiones presentadas. Por lo anterior, la discusión en torno a si los derechos sociales son fundamentales o no, se entiende superada tanto por la jurisprudencia como por la doctrina que soportan el presente trabajo.

El trabajo se desarrolla en tres puntos. En primer lugar, se estudia la concesión de prestaciones individuales basadas únicamente en el carácter subjetivo de los derechos sociales fundamentales en la jurisprudencia de la Corte Constitucional. En segundo lugar, se analizan los desaciertos interpretativos de los derechos sociales en la Corte Constitucional de Colombia a la luz de las críticas doctrinarias realizadas a las decisiones del Supremo Tribunal Federal de Brasil. Finalmente, dando paso a las consideraciones finales, se indaga sobre el riesgo de la inherencia en las competencias constitucionales sobre el poder ejecutivo y el poder legislativo, así como la posible configuración de un comportamiento judicial riesgoso en los tribunales constitucionales.

\section{La concesión de prestaciones individuales basadas únicamente en el carácter subjetivo de los derechos sociales en la Corte Constitucional}

Desde el año 1992, la Corte Constitucional colombiana ha dado giros a su jurisprudencia con un amplio margen de entendimiento alrededor de los derechos sociales. Inicialmente, excluyó el reconocimiento de su fundamentalidad justificando que estos derechos estaban circunscritos al mundo de las mayorías políticas. Asimismo, que su aplicación debía ser confiada al legislador para establecer el significado del texto constitucional; por tal razón, no podían ser considerados fundamentales en sí mismos, excepto en situaciones específicas, en las que se presentara una conexión con un principio o un derecho fundamental (tesis de la conexidad) ${ }^{3}$. De igual forma, se justificó que estos derechos implican una prestación por parte del Estado, lo que se traduce en una erogación económica dependiente de una decisión política; así, esta posibilidad debía resolverse dentro de una lógica de la razonabilidad, teniendo en consideración la condición de escasez de los recursos, los propósitos de igualdad y justicia social, enfrentando un problema de justicia distributiva de carácter político a la hora de distribuir y asignar los recursos ${ }^{4}$.

\footnotetext{
${ }^{3}$ Consistía en aceptar como fundamentales aquellos derechos que no son explícitamente fundamentales en la Constitución de 1991, no obstante, se califican como tal, en virtud de su relación/conexión esencial con otros derechos fundamentales.

${ }^{4}$ Se resaltan algunas decisiones jurisprudenciales en esa línea argumentativa: Corte Constitucional de Colombia, Sentencia de Tutela no 406, 2007; Corte Constitucional de Colombia, Sentencia de Tutela no 570, 1992.
} 
A pesar de lo unánime que parecía estar la jurisprudencia, en 1997, con la decisión correspondiente al control de constitucionalidad del Protocolo de San Salvador5, la Corte Constitucional determinó que no es totalmente correcto considerar que sólo los derechos sociales implican prestaciones positivas del Estado y contrariamente, los derechos de libertad únicamente generan deberes de abstención. Entendió que, el Estado tiene frente a los particulares tanto deberes de abstención como deberes de prestación y promoción para asegurar condiciones materiales mínimas encaminadas a satisfacer la dignidad. La decisión analizó el deber de realización progresiva de los derechos, el cual relaciona un contenido esencial de los derechos sociales, obligando al Estado a garantizar un mínimo vital y a adquirir un compromiso para tomar las medidas necesarias para la adecuada distribución y asignación de los recursos.

A partir del 2007 se reafirma la posición ilustrada con la jurisprudencia de 1997, bajo el entendido de que todos los derechos son objeto de abstención, prestación y promoción. Se sustentó que la naturaleza fundamental de determinado derecho o posición jurídica de carácter social no depende de cómo se hace efectiva, pues lo importante no es el efecto producido, sino la sustancia que lleva a la misma. Lo trascendental de esta decisión consistió en el giro de la jurisprudencia al considerar que la totalidad de los derechos vertidos en la Constitución son considerados fundamentales ${ }^{6}$. A pesar de ello, si se analizan de forma general las disposiciones constitucionales, principalmente, el artículo 2, por medio del cual se consagran los fines esenciales del Estado, dentro de estos, "promover la prosperidad general y la efectividad de los principios, derechos y deberes consagrados en la Constitución”, los cuales se enmarcan dentro del título de los "principios fundamentales", tanto el resultado de la efectividad de todos los derechos, incluidos los económicos y sociales, como su esencia misma corresponden a un principio fundamental, de ahí que su fundamentalidad es explícita en la Constitución.

Para sustentar ese último argumento, vale la pena resaltar, que tanto principios como reglas hacen parte de la estructura de las normas de derechos fundamentales. Asimismo, más allá de que ambas dicen lo que debe ser, su distinción es un asunto entre dos tipos de normas, sustentándose normalmente en el criterio de la generalidad. Según ese criterio, los principios son normas de un grado relativamente alto, en cuanto a las reglas, estas contienen un grado más

${ }^{5}$ Corte Constitucional de Colombia, sentencia de Constitucionalidad C- 251, 1997.

${ }^{6}$ Corte Constitucional de Colombia, Sentencia de Tutela T-016, 22 de enero de 2007. En ese sentido también, Gutiérrez (2010), pp. 81-104. El autor analiza la decisión para desvirtuar el argumento según el cual los derechos económicos, sociales y culturales recogen en todos los casos, reclamaciones encaminadas a la consecución de prestaciones concretas, lo que les atribuye la diferencia con los derechos de libertad. 
bajo. Con todo y los demás criterios de distinción, tales como su origen, su determinabilidad, el carácter explícito de su contenido axiológico, etc., se defiende la tesis por la cual su diferencia no corresponde con un asunto gradual sino cualitativo, lo que supone que los principios son mandatos de optimización que son caracterizados por poder ser satisfechos en diversos grados dependiendo de las posibilidades fácticas y jurídicas, mientras que las reglas son normas que siempre son satisfechas o no7.

De acuerdo con lo anterior, el hecho de que el Constituyente haya establecido la promoción de la prosperidad general y la efectividad de todos los principios, derechos y deberes en la Constitución como principios fundamentales, significa que la efectividad de los derechos sociales del Título II, se evidencia porque son normas fundamentales por expreso mandato constitucional, de ahí su contenido y esencialidad8.

Al reconocer su fundamentalidad, en lo que se refiere a la judicialización de los derechos sociales, las posiciones no son unánimes, o a lo menos acertadas. De acuerdo con Rodolfo Arango, la garantía de condiciones materiales para el reconocimiento de los derechos fundamentales sociales por parte de la jurisprudencia de la Corte Constitucional, corresponde con dos aspectos relevantes, por un lado, las condiciones individuales de debilidad manifiesta y, por el otro, las situaciones estructurales de déficit del mercado. Tanto la una como la otra destacan la situación de urgencia y activan la exigibilidad judicial de las obligaciones positivas en cabeza del Estado ${ }^{9}$.

De igual manera, tanto las condiciones individuales como las situaciones estructurales no requieren únicamente de una actuación normativa concreta y previa por parte del Estado para su satisfacción, pues presuponen que el titular de determinada posición jurídica, justifica la garantía de su derecho a partir de una lectura integral del ordenamiento jurídico. A su vez, esa justificación de la posición jurídica resulta ser compatible con la subsunción del concepto de derechos fundamentales sociales en el de derechos subjetivos ${ }^{10}$.

Esa vinculación directa del concepto de derechos fundamentales sociales en el de derechos subjetivos tiene relación con el protagonismo de la Corte Constitucional en la vida política colombiana, un protagonismo catalogado muchas veces de progresista, ganando un amplio prestigio en sectores de la población críticos frente a los órganos de representación popular, que

\footnotetext{
${ }^{7}$ Alexy (2014), pp. 89-100.

${ }^{8}$ Esta interpretación puede ser compatible con una interpretación holística constitucional, presentada por Rodolfo Arango con base en las ideas de Ronald Dworkin en su obra Freedom's Law. The Moral Reading of the American Constitution. Arango (2001), p. 188.

${ }^{9}$ Arango (2001), p. 206.

${ }^{10}$ Arango (2001), p. 70.
} 
han visto en las decisiones de la Corte Constitucional una oportunidad para la protección de sus derechos $^{11}$. De entrada, podría argumentarse que para aquellos que defienden un protagonismo de la Corte Constitucional, se han surtido transformaciones sociales de carácter significativo a partir de sus decisiones, no obstante, tanto las demandas sociales radicadas ante la Corte Constitucional como las órdenes de desacato a los fallos de tutela mantienen una tendencia en alta, lo que de alguna forma desvirtuaría este argumento.

Por otro lado, esa entrada debe leerse con especial cuidado, pues debido a las razones históricas que antecedieron la institucionalidad de la Corte Constitucional, al amplio reconocimiento ciudadano del control de constitucionalidad y de la acción de tutela, la reivindicación de los derechos, principalmente de derechos fundamentales sociales en Colombia, debe tener en cuenta varios factores, entre ellos, la tradición del control de constitucionalidad ciudadano, la facilidad del acceso a la justicia constitucional 12 , el reforzamiento de las desigualdades sociales y económicas y las asimetrías políticas y culturales.

Con relación a las desigualdades sociales y económicas, Colombia es un país con una nula presencia estatal en muchas regiones. Debido a estas disparidades, sumado al fortalecimiento de la violencia13, se ha evidenciado una influencia directa en el aumento de la pobreza, a través de la destrucción de la vida y de la infraestructura destinada a la previsión de bienes públicos ${ }^{14}$.

Esa realidad que develó el conflicto, que también motivó la urgencia del Constituyente, trajo consigo la consagración de un catálogo de derechos y su garantía delante de la justicia constitucional. A pesar de este avance, la realidad aún demuestra que no hay una plena igualdad material. Los derechos sociales solo están al alcance de una parte de la sociedad, debido a una histórica restricción presupuestal y a una inequitativa distribución o elección de prioridades presupuestales ${ }^{15}$. Esto no implica que las conquistas constitucionales de 1991 sean en vano, por el contrario, han sido el baluarte ciudadano para la exigencia al Estado de la abstención,

\footnotetext{
${ }^{11}$ García y Uprimny (2002), pp. 298-339.

12 Sobre el control de constitucionalidad como una herramienta para la defensa de la legitimidad democrática, la apertura de los tribunales a los ciudadanos y su consolidación en el diálogo público, véase de forma particular: Roa (2019). Asimismo, con relación a la acción de tutela y su reconocimiento procesal dentro de las directrices del constitucionalismo contemporáneo véase: Botero (2009). Por su parte, estos mecanismos se han erigido en términos generales como una forma de seguro, aunque de cierto sector de la población, frente a las injusticias o a las incertezas políticas del país, lo que de alguna manera deja sobre el análisis el real índice de acceso afectivo a la justicia ¿Justicia para quién? ¿para uno o para todos? Véase sobre el asunto las particulares históricas sobre el judicial review. Gill y Cutlher (2014), pp. 78.

${ }^{13}$ CNMH (2018), pp. 11.

${ }_{14}$ Galindo, Restrepo y Sánchez (2009), pp. 319.

${ }^{15}$ De acuerdo con el economista Salomón Kalmanovitz, "Las limitaciones presupuestales se explican no sólo por la pobreza del país sino por el clientelismo como sistema de gobierno que no goza de la legitimidad suficiente para que mucha gente y los ricos cumplan con sus deberes tributarios. Ello ya nos revela que la plenitud de los derechos puede ser demagógica". Kalmanovitz (2000).
} 
promoción y prestación de sus derechos ${ }^{16}$. No obstante, la garantía progresiva de los derechos aún es insuficiente, insuficiencia tal que se acrecienta cuando se examina el papel de la Corte Constitucional frente a la reducción de las desigualdades y la promoción de la prosperidad general.

La respuesta preliminar a ese análisis merece ser observada a partir de algunos casos concretos, no obstante, va encaminada a confirmar la hipótesis propuesta al inicio. En ese sentido, se analizarán de forma general algunas decisiones relativas a la prestación de servicios públicos para la promoción y prestación de los derechos fundamentales.

La Corte Constitucional ha sido reiterativa en manifestar que la naturaleza o condición programática de los derechos sociales tiende a transmutarse hacia un derecho subjetivo, en la medida que crea elementos que le permitan a una persona exigir del Estado el cumplimiento de su deber asistencial, al obligarle a ejecutar prestaciones determinadas a favor de un sujeto específico ${ }^{17}$. Esa denominada "transmutación en garantía subjetiva" de los derechos sociales, acompaña la tesis de la conexidad respecto de un derecho sobre el cual no existe discusión alrededor de su naturaleza fundamental o por la afectación al mínimo vital18. En ese sentido, la Corte ha determinado que, si bien existen responsabilidades económicas de financiación, racionalización y uso del sistema destinado para cada derecho, esas responsabilidades no pueden convertirse en una barrera invencible para el reconocimiento de prestaciones; pues, mermaría las posibilidades de que las personas pobres puedan sufragar costos de acceso a los servicios ${ }^{19}$.

\footnotetext{
${ }^{16}$ Una visión menos pesimista reconoce que si bien las guerrillas, el narcotráfico, el paramilitarismo, la corrupción, la violencia, el desplazamiento, etc., marcaron de manera negativa la vida colombiana, se han dado avances paulatinos en materia de reducción de la tasa de pobreza, del analfabetismo, la mortalidad de vida, el aumento de la expectativa de vida y de los servicios públicos. Perry (2019).

${ }^{17}$ En ese sentido; Corte Constitucional de Colombia, Sentencia de Tutela T-880, 30 de noviembre de 2009. De acuerdo con la decisión, la accionante acude ante la justicia constitucional con el propósito de obtener el amparo de sus derechos fundamentales a la vida, a la salud y a la seguridad social, cuando la Entidad Promotora de Salud se niega a autorizar la práctica de una e ndoscopia digestiva superior más dilatación neumática y el suministro de medicamentos con ocasión de un Bypass gástrico, bajo el argumento de que se encuentran fuera del Plan Obligatorio de Salud - POS-. La Corte, reconociendo el derecho fundamental a la salud, reconoce que si bien los recursos del sistema de salud son limitados, por esta razón, la jurisprudencia ha señalado que en los casos de procedimientos fuera del POS, los primer llamados a proveerse lo necesario es la persona y en aquellos eventos en los que no cuente con los recursos, le corresponde al Estado garantizar la efectiva concreción del derecho. En ese sentido, orden a la entidad de salud autorizar la práctica del examen que se encuentra fuera. En sentido similar pueden verse las decisiones: Corte Constitucional de Colombia, sentencia de Tutela T-662, 10 de agosto de 2006; Corte Constitucional de Colombia, sentencia T-108, 1993; Corte Constitucional de Colombia, sentencia de Unificación SU-819, 1999; Corte Constitucional de Colombia, sentencia de tutela T-041, 1996.

${ }^{18}$ Corte Constitucional de Colombia, sentencia de Tutela T-717, 13 de septiembre de 2012; Corte Constitucional de Colombia, sentencia de Tutela T-304, 1998.

${ }_{19}$ Corte Constitucional de Colombia, sentencia de Tutela T-409, 3 de septiembre de 2019. El caso tiene que ver con un menor diagnosticado con autismo y con perturbación de la actividad y de la atención, quien debe asistir a varias y frecuentes citas médicas para controles, pruebas diagnósticas, exámenes de laboratorio y procedimientos clínicos. Esa prescripción médica, a juicio del accionante, requiere del suministro de transporte especial por cuanto el menor cuenta con hipersensibilidad al ruido, objeto negado por las Entidades Promotoras de Salud y asunto sobre el cual versa el litigio, donde el tribunal opta por la concesión del transporte
} 
Estas manifestaciones jurisprudenciales encuentran fundamento en razones de diferente naturaleza, desde argumentos económicos hasta semánticos o terminológicos. Por un lado, la Corte Constitucional ha señalado que su postura respecto a lo que es un derecho fundamental, ha oscilado entre la idea de que se trata de derechos subjetivos de aplicación inmediata, su inalienabilidad y la esencialidad del derecho a la persona ${ }^{20}$. Sin embargo, la Corte Constitucional resalta que no existe en su jurisprudencia un consenso respecto a qué se entiende por un derecho fundamental21. Esta razón no discute realmente cuáles son los derechos fundamentales, asunto ya presentado. En realidad, la discusión gira en torno a la dimensión y a la titularidad de los derechos, su ejercicio y su reconocimiento por parte de la Corte Constitucional, que ha optado por una postura loable, pero no por eso real, crítica y sensible frente a los derechos inherentes a la persona humana.

En sentido similar, otra de las razones también tiene que ver con la exclusiva e histórica atribución dada a los derechos sociales, cuyos vestigios aún subsisten en el presente. Esta atribución se relaciona con la superada tesis de que los derechos sociales en cuanto mandatos programáticos dirigidos al legislador, se presentan como una categoría opuesta a la de derecho subjetivo, clásicamente atribuible a los derechos de libertad. En ese sentido, aunque desde el 2007 los derechos sociales son fundamentales, por ese hecho, se ha dado una amplia connotación casi que exclusiva al florecimiento de los derechos sociales en tanto derechos subjetivos susceptibles de reclamación judicial ${ }^{22}$.

Dentro de estas razones también se encuentra la vaguedad conceptual que presenta el tribunal entre la afectación del derecho de todos y la garantía de prerrogativas individuales ${ }^{23}$. La tutela de los derechos se enfrenta con una conceptualización de la faceta individual de los derechos para garantizar derechos, que en principio deben ser para todos, principalmente aquellos relativos o efectivos a través de la prestación de los servicios públicos. Argumentar que

\footnotetext{
al menor, ya que la familia del menor se encuentra una posición económica que no le permite sufragar estos costos y el menor es un sujeto de especial protección.

${ }^{20}$ Corte Constitucional de Colombia, sentencia de Tutela T-760, 31 de julio de 2008, la cual toma como fundamento: Corte Constitucional de Colombia, sentencia de unificación SU-225, 1998, Corte Constitucional de Colombia, sentencia de Tutela T-01, 1992; Corte Constitucional de Colombia, Sentencia de Tutela T-462, 1993; Corte Constitucional de Colombia, sentencia de tutela T1306, 2000; Corte Constitucional de Colombia, sentencia de tutela T-227, 2003.

${ }^{21}$ Corte Constitucional de Colombia, sentencia de tutela T-227, 2003.

22 Sobre esa transformación jurisprudencial véase: Gutiérrez (2010), pp. 81-104. Vale la pena también considerar el término de "derechos subjetivos colectivos", que, de acuerdo con la Corte Constitucional de Colombia, sentencia de constitucionalidad C-179, 13 de abril de 1994, son establecidos en favor de grupos o sectores de la sociedad, caracterizados por la existencia de un in terés común, no quiere decir que su tutela sea exclusivamente subjetiva, también requiere de una tutela obj etiva.

${ }^{23}$ Corte Constitucional de Colombia, sentencia de tutela T-479, 15 de octubre de 2019. El caso en análisis pretende tutelar el derecho fundamental al agua potable, a la salud y a la vivienda digna con base en la ausencia de este recurso para una familia. Sobre la misma decisión vale la pena resaltar el salvamento de voto del Magistrado Carlos Bernal Pulido que analiza la conceptualización de la faceta individual del derecho al agua potable.
} 
la exigibilidad de un servicio como derecho fundamental individual alude a la cantidad mínima necesaria para su consumo o satisfacción y que, por esta razón es plausible y preferente la acción de tutela sobre cualquier otro medio, es recaer en la falacia argumentativa que intenta determinar un derecho sobre mínimos, propio del discurso capitalista de bienestar en el constitucionalismo liberal. La razón anterior obedece también a una discusión de carácter procesal, ya que, se pone en discusión la procedencia de una acción individual o colectiva cuando se trata de proteger derechos fundamentales ${ }^{24}$.

Otra de las razones corresponde a las barreras burocráticas de cualquier índole que se anteponen a la tutela administrativa de los derechos sociales ${ }^{25}$. Estas barreras están delineadas por una multiplicidad de solicitudes a título individual que de alguna u otra manera demuestran una gestión y una información poco asequible para los usuarios por parte de los prestadores de los servicios, como es el caso de la salud, dejando evidenciada una prestación ineficiente e ineficaz para la garantía de los servicios. La excesiva judicialización que antecede esta razón, ha visto en el juez constitucional y su intervención, el único medio para garantizar su eficacia individual más que colectiva.

Pueden ser varias las demás razones que justifican el actual entendimiento de la Corte Constitucional en torno al tratamiento de los derechos fundamentales sociales. Ese tratamiento no solo tiene que ver con el tipo de derechos que contempla, discusión ya superada por la Corte Constitucional, sino sobre la titularidad y las dimensiones que acompañan estos derechos. La justiciabilidad de los derechos fundamentales sociales tiene que verse más que como una simple concepción evolucionada de los derechos subjetivos, que permite su reconocimiento a través de una argumentación sustentada en que las posiciones jurídicas fundamentales deben ser reconocidas para no ocasionar un daño inminente a la persona ${ }^{26}$.

Vale la pena advertir hasta aquí, que no se quiere justificar de modo alguno la abstención de la Corte Constitucional cuando una prestación individual llega a su sede para ser decidida, asimismo, que el papel protagonista hasta ahora adelantado por la justicia constitucional ha sido en vano. Por el contrario, el avance en materia de garantía de derechos fundamentales sociales por parte de la misma ha sido destacable, no por eso totalmente deseable en términos de

\footnotetext{
${ }^{24}$ Corte Constitucional, sentencia de tutela T- 209, 17 de mayo de 2019. A través de la decisión se concedió la procedencia excepcional de la acción de tutela para ordenar la construcción de una obra pública por amenaza o vulneración de derechos fundamentales.

${ }^{25}$ Corte Constitucional de Colombia, sentencia SU - 124, 2018.

${ }^{26}$ Arango (2001), p. 206.
} 
reducción colectiva de desigualdades. La extensa actividad judicial no puede ser una excusa para el cumplimiento cabal de las funciones atribuidas a las otras ramas del poder. La necesaria transformación que implica el entendimiento de la titularidad y las dimensiones de estos derechos y su garantía ante la justicia constitucional, debe estar acompañada de un adecuado sistema de controles en cuanto al ejercicio y acceso a la justicia, así como de reformas del sistema jurídico, administrativo y legislativo que estén orientadas a reforzar estos parámetros. No se trata entonces de no proteger o garantizar derechos, por el contrario, lo importante es que se cumpla de forma integral el principio constitucional de la promoción del bienestar general. Sobre ese eje debe centrarse el rol de la justicia constitucional en su papel transformador de desigualdades.

\section{Los desaciertos interpretativos de los derechos sociales en la Corte Constitucional de Colombia a la luz de las críticas realizadas al Supremo Tribunal Federal de Brasil}

Los desaciertos argumentativos de los derechos fundamentales sociales en la Corte Constitucional presentados anteriormente se resumen en los siguientes puntos: la transmutación en una garantía subjetiva de los derechos sociales en cuanto fundamentales, producto de las transformaciones que acompañaron ese reconocimiento iusfundamental. Esa transmutación se identifica, entre otras razones, por la ausencia de una unificación conceptual en torno a la titularidad y dimensionalidad de los derechos fundamentales sociales, la exclusiva e histórica atribución dada a estos derechos, cuyos vestigios aún subsisten en el presente, la vaguedad conceptual que presenta la jurisprudencia entre la afectación del derecho de todos y la garantía de las prerrogativas individuales, y, las barreras burocráticas de cualquier índole que se anteponen a la tutela administrativa de los derechos.

Se tratará de dar énfasis en este capítulo a los cuatro primeros puntos, por cuanto el último se escaparía del objetivo del escrito. Ese abordaje se dará a partir un método deductivo comparado, dando paso al análisis crítico realizado por la doctrina brasilera a decisiones similares del Supremo Tribunal Federal, fundadas en la teoría de los derechos fundamentales sociales, su multifuncionalidad y su doble titularidad.

Los argumentos sobre los cuales se sustenta el diálogo comparado se soportan en las siguientes ideas, entre otras, los derechos fundamentales sociales considerados integralmente 
presentan una faceta individual y una transindividual, dependiendo de la pretensión en análisis ${ }^{27}$, atendiendo a su multidimensionalidad, los derechos fundamentales sociales son más que un mero derecho subjetivo ${ }^{28}$, el entendimiento de la transmutación hacia una garantía subjetiva de los derechos fundamentales sociales corresponde con una resubjetivización de la dimensión objetiva que abre paso a una dimensión subjetiva transindividual ${ }^{29}$.

Para dar desarrollo a los argumentos propuestos, es preciso destacar que el Derecho Público brasilero se caracterizó por determinadas transiciones que caminaron entre la intervención estatal y la subsidiariedad. De acuerdo con Daniel Wunder Hachem, el entrecruzamiento de las tendencias del Derecho Administrativo y del Derecho Constitucional en lo que tiene que ver con el desarrollo social y el protagonismo del poder judicial en cabeza del Supremo Tribunal Federal, tuvo por contexto un periodo posterior a la promulgación de la Constitución de 1988 hasta mediados de la primera década del 2000. Durante ese período operó una revolución en materia de Derecho Público brasilero, correspondiente con las transformaciones del Derecho Constitucional europeo continental a partir de la segunda mitad del siglo XX, en otras palabras, un "neoconstitucionalismo" formado a partir del paradigma de la centralización y valorización de la dignidad de la persona humana, generando el Derecho Constitucional de la efectividad, que analizaba la eficacia jurídico-social de las disposiciones constitucionales.

Sobre ese prisma, la influencia de la hermenéutica constitucional más allá de la ley formal, del Derecho Internacional de los Derechos Humanos ${ }^{30}$, así como la idea de la sujeción del Poder Público a la juridicidad en cuanto a la posibilidad del control judicial de la actuación de la Administración Púbica, el Derecho Constitucional de la efectividad se caracterizó también por una perspectiva individualista del Derecho Administrativo, que dio paso a un problema de inefectividad en cuanto a la posibilidad de reivindicación individual de prestaciones estatales para la satisfacción de los derechos sociales. Se entendió que la aplicabilidad inmediata de la que gozan los derechos fundamentales, de acuerdo con la referencia literal del artículo $5 \S 1$ de la Constitución de 1988, condujo a reclamar judicialmente la realización de los derechos frente a omisiones administrativas ${ }^{31}$.

\footnotetext{
${ }^{27}$ Hachem (2013), p. 619.

${ }^{28}$ Hachem (2013), p. 625.

${ }^{29}$ Hachem (2013), p. 653.

30 Sobre el asunto particular de la influencia del Derecho Internacional de los Derechos Humanos, en particular de la Corte Interamericana de Derechos Humanos en la jurisprudencia del Supremo Tribunal Federal véase: Ferreira y Fernandes (2013), pp. 23-45; para el caso de Colombia, Gutiérrez (2010), p. 89.

${ }^{31}$ Para un análisis sobre esas transformaciones del Derecho Público brasilero véase Hachem (2013), pp. 133-168. Asimismo, Hachem (2013), pp. 340-399.
} 
La adopción de esa postura individualista caracterizada por una amplia intervención judicial, orientada a la concesión de prestaciones estatales positivas dirigidas a la garantía efectiva e individual de los derechos sociales fundamentales, por dar un ejemplo, las decisiones relativas a la concesión de tratamientos de salud de alto costo o en el exterior, colocaron en jaque la capacidad financiera de la Administración Pública e imposibilitaron la tutela efectiva administrativa de estos derechos ${ }^{32}$. Esa judicialización a grande escala sentó las discusiones alrededor de las funciones del Supremo Tribunal Federal como tribunal constitucional y su entendimiento sobre la titularidad, dimensionalidad y la multifuncionalidad de los derechos fundamentales sociales, resumidas de forma aproximada en los argumentos propuestos, los cuales no son taxativos, pues aceptan otras ideas encaminadas a justificar esa idea.

El primer argumento propuesto consiste en que los derechos fundamentales sociales considerados integralmente presentan una faceta individual y una transindividual, dependiendo de la pretensión en análisis. Sobre ese punto, Daniel Wunder Hachem resalta que el reconocimiento radical subjetivo de todos los derechos fundamentales en el contexto brasilero posterior a la Constitución de 1988, posibilitó una sindicabilidad judicial que a su vez se compaginó con un abandono de la fuerza jurídica y normativa de las disposiciones constitucionales, generando un desamparo administrativo a los titulares de los derechos por la omisión estatal. Esa sindicabilidad no desvirtuó de modo alguno la existencia de una perspectiva subjetiva de los derechos sociales, por el contrario, el asunto crítico consistió en la centralización de la garantía y defensa de estos derechos sobre la dimensión subjetiva. En otras palabras, lo que ocurrió fue una absorción del discurso doctrinario que dio protagonismo a la titularidad y, por ende, la exigencia de los derechos, sin tener en cuenta los efectos jurídicos de la dimensión objetiva de los mismos ${ }^{33}$.

Los efectos que trajo consigo esa centralización sobre la dimensión subjetiva corresponde con una serie de mitos y confusiones en la teoría de los derechos fundamentales. Entre ellos, la idea que supone la titularidad transindividual de esos derechos. Siguiendo con lo analizado por el mismo autor, lo que conduce a esos mitos y confusiones corresponde con la atribución histórica mal fundada de que sólo los derechos de libertad poseen una función de defensa, los sociales una prestación fáctica y los colectivos, como el derecho al medio ambiente sano, una

\footnotetext{
32 Según el autor, estas decisiones, como la concesión de tratamientos de alto costo en el exterior, han sido fundamentadas más en razones de emoción que con razón, siendo incongruentes y desmedidas, que acaban por dejar en jaque la consecución de las políticas públicas, perjudicando no únicamente un empleo racional de los recursos públicos sino la garantía y prestación universal de los derechos fundamentales: Supremo Tribunal Federal, medida Cautelar No. 1246, 1997; Hachem (2013), p. 145.

${ }^{33}$ Hachem (2013), pp. 631-632.
} 
titularidad transindividual, cuando lo cierto es que todas las características son atribuibles a todos los derechos considerados como fundamentales. En efecto, lo que intenta dar luz a la confusión consiste en entender la diferencia que existe entre un derecho fundamental en sentido amplio y en sentido estricto. Un derecho fundamental en sentido estricto corresponde a cada una de las posiciones jurídicas de ese derecho, mientras que en sentido amplio hace referencia al conjunto de posiciones fundamentales en las cuales el ordenamiento jurídico inviste a un titular de un derecho, en últimas, lo amplio radica en entender los derechos fundamentales como un todo ${ }^{34}$.

Sobre ese argumento, esto es, entender que del derecho fundamental como un todo (sentido amplio), se despliegan una serie de posiciones jurídicas que son fundamentales (sentido estricto). Vale la pena analizar entonces, lo que se relaciona con su transindividualidad. En otras palabras, si en razón de la dimensión subjetiva, cada norma atribuye una variedad de pretensiones jurídicas fundamentales que pueden ser exigidas individualmente, lo cierto también es que por la dimensionalidad objetiva se resaltan valores y fines cuya satisfacción se obliga a los otros poderes públicos de carácter oficioso. Ahí radica el asunto de la faceta transindividual de los derechos sociales y en general de todos los derechos fundamentales, a partir de la cual se deriva el deber objetivo de que la Administración cree condiciones necesarias para el goce de los derechos de forma universal y colectiva ${ }^{35}$.

Una vez analizada la titularidad individual y transindividualidad, dando relevancia a la posibilidad de que la garantía de los derechos se de en sede colectiva, reconociendo la necesidad de alertar la Administración de su deber de tutela efectiva y al legislador de su clarificación en torno a las posiciones jurídicas fundamentales, es importante resaltar que no significa que no exista una dimensión subjetiva, sino que lo deseable es, atendiendo a la multidimensionalidad de los derechos fundamentales, que los derechos sociales se tengan más que un mero derecho subjetivo, pues recaería en su excesiva judicialización, entorpeciendo el adecuado funcionamiento de la justicia. Así pues, Daniel Wunder Hachem destaca que es imperativa la

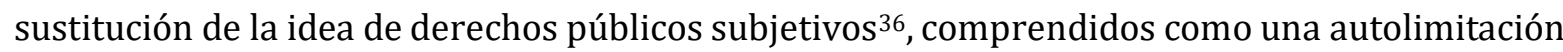

\footnotetext{
${ }^{34}$ Hachem (2019), p. 409; Alexy (2014), pp. 89-100.

${ }^{35}$ Hachem (2013), pp. 641-643.

${ }^{36}$ La idea de "derechos públicos subjetivos" corresponde con una doctrina decimonónica, que consiste, en palabras generales, en un vestigio de la teoría de los derechos fundamentales en el liberalismo al final del siglo XIX, formulada por Georg Jellinek, sobre la cual se buscaba superar el iusnaturalismo que acompañaba los "derechos del hombre" y dotarlos de fuerza normativa, generando así autolimitaciones establecidas por el Estado a su poder soberano orientados a garantizar estos derechos. El asunto crítico radica, de acuerdo con Hachem, en la trasposición a esta idea de presupuestos metodológicos de Derecho Privado, con un amplio énfasis en el carácter individual de estos derechos. Hachem (2019), pp. 412-413.
} 
del poder soberano del Estado en pro de las esferas delimitadas de intereses privados individuales, por la noción jurídica y autónoma de los derechos fundamentales. Esa imperativa sustitución encuentra fundamento, entre otras cosas, en las transformaciones que trajo consigo la consagración de un Estado Social de Derecho, destacable en la Constitución brasilera de 1988 y en la colombiana de 1991, que implicó la necesidad de atribuirle fundamentalidad a los derechos sociales. Ese quizá, fue el origen de las discusiones en sede de la Corte Constitucional de Colombia, pues si bien las decisiones que debía tomar se enfrentaban a un nuevo modelo social de Estado, los vestigios individualistas no permitían comprender que los derechos sociales per se eran derechos fundamentales. Y si bien esa idea se superó en el año 2007, la teoría a la práctica no tuvo una transformación sustancial, por cuanto, como se trató de ver, se siguió dando prevalencia a un carácter subjetivo de estos derechos por el solo hecho de ser fundamentales, generando implicaciones diversas, como la afectación presupuestal para la garantía universal y espontánea de los derechos por parte de la Administración Pública.

Aunque el amplio reconocimiento de la dimensión objetiva de los derechos se ha dado prevalentemente en sede de unificación jurisprudencial, los riesgos no disminuyen, ya que, asume un papel legislativo protagonista, delineador de posiciones jurídicas fundamentales, que corresponde en primer lugar al legislativo, como escenario por excelencia de la discusión democrática.

Por lo anterior, una proposición que ponga equilibrio en la tensión aún existente entre derechos subjetivos y objetivos, así como en la titularidad individual y transindividual, parte de los límites y controles en materia de control jurisdiccional de la actividad administrativa, siempre tomando como sustento las disposiciones constitucionales ${ }^{37}$. De acuerdo con ese propósito, se denota que el entendimiento o consideración de los derechos sociales como derechos subjetivos, cuando individual o subjetivamente se activa la justicia constitucional, deviene en un asunto de pérdida de legitimidad de concretización de los derechos individuales de libertad, además de que se aparta del reconocimiento social superior de la prevalencia del interés general o superioridad de la comunidad.

Con todo, si de acuerdo con los postulados de la Constitución de 1988, se reconoce un principio de supremacía del interés público ${ }^{38}$, ese interés debe atender a una

\footnotetext{
${ }^{37}$ Sobre el control jurisdiccional de las políticas públicas véase Bitencourt (2013), pp. 109-182; Bitencourt (2015), pp. 143-166; Soares (2011), pp. 121-150.

38 Gabardo (2017), pp. 95-130.
} 
multidimensionalidad observada a partir de una fusión entre las dimensiones subjetivas y objetivas de las normas que garantizan los derechos fundamentales. Así, como lo destaca Daniel Wunder Hachem, es posible develar una visión panorámica de la norma de derecho fundamental, que incluye diferentes pretensiones subjetivas, en conjunto (sentido amplio) o individualmente consideradas (sentido estricto), así como deberes objetivos deducibles de las disposiciones constitucionales sobre los derechos fundamentales. El reconocimiento del derecho fundamental como un todo, implica entender que todos los derechos fundamentales poseen las características (promoción, abstención, prestación fáctica y normativa) y la titularidad históricamente atribuibles a las superadas generaciones de derechos de forma independiente 39 .

Vale la pena reiterar que lo expuesto hasta aquí no se aparta del reconocimiento de que diferentes pretensiones jurídicas de derecho fundamental sean susceptibles de una reclamación judicial individual y que otras posiciones sean reivindicables a través de instrumentos de tutela colectiva o transindividual. Lo relevante consiste en que no es adecuado reducirlos en su totalidad a la condición de derechos subjetivos individuales para su garantía judicial. En otras palabras, en argüir judicialmente una posición o pretensión jurídica fundamental sin ser demostrada ${ }^{40}$. De ahí que, para los que defienden la importancia de amparar derechos o una posición jurídica de un derecho fundamental sobre una dimensión subjetiva por la transmutación misma a la que es sujeta un derecho social, deben analizar los límites y los factores que impone la resubjetivización de la dimensionalidad objetiva y de ahí el reconocimiento de su multifuncionalidad y transindividualidad.

El entendimiento de la transmutación hacia una garantía subjetiva de los derechos fundamentales sociales corresponde con una resubjetivización de la dimensión objetiva que abre paso a una dimensión subjetiva transindividual o colectiva.

La existencia objetiva de un derecho integra facetas subjetivas e individuales, lo mismo es, un derecho fundamental como un todo integra un conjunto de posiciones o pretensiones fundamentales independientes. No obstante esa existencia, la norma solo puede estar orientada a la garantía o satisfacción de esa posición o pretensión fundamental independiente subjetiva por la propia consagración o por el reconocimiento de valores en las normas de derechos fundamentales ${ }^{41}$. El problema radica cuando esa transmutación hacia una garantía subjetiva,

\footnotetext{
${ }^{39}$ Hachem (2019), p. 428.

${ }^{40}$ Hachem (2019), p. 429.

${ }^{41}$ Novais (2003), pp. 70-75.
} 
(muchas veces alegada por la necesidad de garantizar un derecho fundamental al mínimo existencial o vital, como sucede en Colombia ${ }^{42}$, al justificar que el Estado debe responder frente a las urgencias que se le presenten) requiere justificar el grado de exigibilidad de esa pretensión; es decir, la cuestión radica en determinar cuándo pueden ser exigibles las pretensiones jurídicas individuales frente a la ausencia de una consagración o un reconocimiento de valores en las normas de derechos fundamentales.

Así pues, cuando se afirma que algunas pretensiones ligadas a un derecho fundamental son exigidas a partir de una titularidad individual y que otras derivadas del mismo derecho merecen una garantía a partir de una titularidad transindividual, se debe considerar que, a pesar del grado de inobservancia de las imposiciones constitucionales objetivas, puede darse lugar a una reconducción objetiva para la tutela subjetiva de pretensiones jurídicas de naturaleza transindividual cuando el Estado no observe el derecho ${ }^{43}$.

Entiéndase a través de un ejemplo, si a partir de la faceta o la perspectiva objetiva de un derecho fundamental como un todo (si se reconoce el derecho a la vivienda digna como un todo, desprovisto de cualquier contenido específico), y a su vez, ese reconocimiento implica la abstracción de diferentes posiciones jurídico subjetivas (se abstrae cualquier contenido específico inmerso en el derecho a la vivienda digna), la existencia de un derecho subjetivo dirigido al Estado resultaría entonces derivado o inmerso en esa dimensión o perspectiva objetiva (la creación legal de un programa especial de acceso a la vivienda de forma gratuita para madres cabeza de familia desplazadas por la violencia resulta del derecho a la vivienda digna, por ejemplo). Ahora bien, si el Estado incumple ese deber impuesto (derivado del derecho a la vivienda digna), puede generar una posición subjetiva (supóngase el caso que a una madre cabeza de familia desplazada por la violencia se le impide el acceso a obtener una vivienda digna, se crea una posición subjetiva en cabeza de ella), que le permite exigir ante el Estado el cumplimiento de la obligación amparada por la dimensión objetiva ${ }^{44}$.

Con base en los supuestos ejemplificados anteriormente, se debe tener en cuenta que la determinación y admisión de esas obligaciones en cabeza del Estado se encuentran en un primer

\footnotetext{
42 El derecho al mínimo vital "deriva de los principios de Estado Social de derecho, dignidad humana y solidaridad, en concordancia con los derechos fundamentales a la vida, a la integridad personal y a la igualdad. Este derecho adquiere relevancia en situa ciones humanas límites, relativas a la extrema pobreza y la indigencia, cuando frente a las necesidades más elementales y humanas, el Estado y la sociedad no responden de manera congruente". Corte Constitucional de Colombia, sentencia T- 716, 2017. Para un análisis del mínimo "existencial" en Brasil, Bitencourt (2010), pp. 99-163; Sarlet y Zockun (2016), pp. 115-141; Hachem (2014), pp. 93-138.

${ }^{43}$ Hachem (2013), pp. 652-653.

${ }^{44}$ Hachem (2013), pp. 652-653.
} 
lugar, dentro de la libre conformación legislativa y la discrecionalidad administrativa frente a la concreción normativa de cada pretensión jurídica, sujetas a la reserva de lo políticamente oportuno, y en segundo lugar, sujetas a determinadas reservas jurídicas y fácticas.

Sobre el primero, basta reiterar que las posiciones jurídicas derivadas de un derecho fundamental como un todo pueden presentar una faceta subjetiva, exigible judicialmente a partir de los contextos normativos adecuados por la Constitución, la ley o los actos administrativos, eso implica un grado específico de determinabilidad de la conducta 45.

Otro asunto relevante es cuando esto no está claro, que es la tendencia mayoritaria en la concesión de prestaciones individuales por parte de los tribunales. En ese caso de ausencia, se debe sujetar a algunas reservas fácticas y jurídicas dependiendo de la pretensión o posición jurídica concreta en sede de tutela. En ese caso, operaría la reserva inmanente de ponderación para indagar la dimensión del peso de las normas de derechos fundamentales, la reserva de lo políticamente adecuado u oportuno, el cual, contempla la posibilidad de alertar al Poder Público en la generación de políticas públicas sobre el asunto, lo que de entrada coloca un límite a cualquier prestación que conoce la justicia constitucional, y la reserva de lo financieramente posible, como verdadero juicio sobre la distribución presupuestal para garantizar la necesaria continuidad de las políticas de Estado que regulan posiciones de derechos fundamentales, que no pueden ser objeto de retroceso injustificado ${ }^{46}$. Al final, los caminos que presenta la tutela administrativa efectiva, universal y espontánea de los derechos fundamentales como un todo, en cabeza del Poder Púbico político, se hacen obligatorios para mantener el equilibrio y la armonía de los poderes, asegurando el carácter democrático de los derechos fundamentales, pues a eso responde su historia, a una lucha más política que judicial. El debate aún opera sobre la inmediatez, la procesalidad o la opción procesal para hacer valer los derechos y la subsidiariedad de los mecanismos judiciales en aras de garantizar los derechos fundamentales.

\footnotetext{
${ }^{45}$ Hachem (2019), p. 429.

${ }^{46}$ Jorge Reis Novais, al analizar las objeciones a la reserva de lo financieramente posible, parte del supuesto de que la escasez que enfrentan los países para la garantía de los derechos sociales no es absoluta, ni aún en un Estado en condiciones de normali dad, siempre se va a argumentar la falta de recursos. En ese caso, al ser moderada, el problema radica entonces en la "definición de prioridades", "escogencias políticas en la distribución de los recursos y de las necesidades". Novais (2010), p. 105. Con relación a un análisis sobre las reservas fácticas y jurídicas. Hachem (2019), pp. 431-433. Y, concretamente sobre la reserva de lo posible Sgarbossa (2010), pp. 127-145.
} 


\section{Consideraciones finales: Los riesgos de garantía judicial de los derechos sociales y las implicaciones sobre el comportamiento judicial de los tribunales constitucionales}

La relación que existe entre la exclusiva tutela individual o subjetiva de los derechos sociales en la jurisprudencia tanto del Supremo Tribunal Federal como de la Corte Constitucional genera o avizora el riesgo de alterar el comportamiento judicial. En cuanto a Brasil, la lógica que llevó a una judicialización desenfrenada, consistió en una sublevación de la corriente neoconstitucionalista que partía del supuesto de que si la Constitución o su interpretación judicial ${ }^{47}$ prevé un derecho social entre los derechos fundamentales, este deberá ser comprendido exclusivamente como un derecho subjetivo, de esa manera, su exigibilidad judicial sería plena ${ }^{48}$.

En Colombia, el comportamiento progresista asociado a la garantía de los derechos sociales está vinculado a pretensiones que implican una erogación pecuniaria. Es decir, aquellas que no resultan de una obligación previa; por lo tanto, aparta el progresismo del pago de lo debido como un efecto de la obligación con fuente legal o constitucional. En otras palabras, si previamente existe en la ley o en la Constitución una obligación —mismo que general- por parte del Estado orientada a satisfacer derechos sociales, la sola existencia de esa obligación, genera como efecto la exigencia judicial para cobrar el pago de lo debido. Atendiendo a lo anterior, Saffon y GarcíaVillegas proponen una diferencia entre decisiones sobre derechos sociales que implican un pago de lo debido, es decir, estableciendo si el accionante tiene un derecho de pago a su favor en cabeza del Estado y decisiones sobre derechos sociales prestacionales en sentido estricto, que corresponde con los casos en que la decisión económica que ordena el juez no resulta de una obligación preexistente, sino que considera necesario que se cumpla con la obligación fundada en una erogación económica no preestablecida, sólo en éste último caso podría hablarse de "activismo judicial ${ }^{49 "}$.

La postura anteriormente propuesta resulta parcialmente válida. En principio, es válida la concesión de prestaciones que, aunque fundadas en una faceta objetiva, pueden prestar una faceta subjetiva, exigible judicialmente a partir de los contextos normativos que determinan un grado específico de una conducta objeto de la obligación. Ahora bien, lo que hace parcial esa

\footnotetext{
${ }^{47}$ Para Robert Alexy existen normas de derecho fundamental atribuidas o derivadas. Esa norma atribuida es válida, es una norma de derecho fundamental bajo una correcta fundamentación referida a los derechos fundamentales. Alexy (2014), p. 74.

${ }^{48}$ Hachem (2019), p. 414.

${ }^{49}$ Saffon y García-Villegas (2011), pp. 91-94.
} 
validez, consiste en entender los derechos sociales únicamente como prestacionales con base en una fuente normativa que constituye una obligación. Eso lleva a una comprensión equivocada de la autoridad argumentativa, según la cual, los derechos sociales son derechos fundamentales como un todo y todos tienen una doble faceta (individual y transindividual) y una multidimensionalidad. Asimismo, que los derechos fundamentales como un todo son objeto de abstención, promoción, prestación normativa y económica. Por otro lado, los criterios sobre los cuales se determinan qué tipo de decisiones son "activistas" o no, no reconoce los tropiezos que genera reconocer una dimensión exclusiva subjetiva de los derechos sociales.

Con base en lo anterior vale la pena destacar cuatro puntos:

En primer lugar, la ineficacia de la Administración Pública o la inoperancia del legislativo, en lo que tiene que ver con la garantía de los derechos sociales, no puede justificarse o ver remedio absoluto en el protagonismo del Supremo Tribunal Federal o de la Corte Constitucional. Pues, así como el ejecutivo y el legislativo son generalmente falibles, los jueces también son susceptibles de comportamientos antiéticos, inclusive solipsistas. Si históricamente los tribunales se han mostrado como "héroes" dentro de una democracia, es muy probable que ese heroísmo se vaya desdibujando en otro período por las razones ya expuestas.

En segundo lugar, cuando el tribunal constitucional opta por dar una prevalencia a la faceta o a la dimensión objetiva de los derechos fundamentales sociales, tendencialmente parece cobijar sus decisiones en sentencias estructurales y de unificación, a través de las cuales declara, ordena y crea instrumentos normativos con el objetivo de extender los efectos (inter comunis) de esas decisiones a toda la sociedad o a los sujetos de la misma que identifiquen en los elementos del fallo elementos comunes a su pretensión. De forma indiscutible podría reconocerse un avance en la forma a través de la cual se da prevalencia a la dimensión objetiva de los derechos como una garantía de derechos para todos más que para unos. El problema radica entonces en las amplias competencias auto-atribuidas de los tribunales en asuntos que, en primer lugar, corresponden al escenario y al debate político en sede legislativa o en la discrecionalidad administrativa. Si los jueces no son representantes directos del pueblo, tampoco pueden ocupar el papel de los órganos políticos constitucionalmente establecidos.

En tercer lugar, resulta interesante analizar la falta de inmediatez de la justicia que acompaña la opción de que la exigibilidad judicial de los derechos sociales se sujete a determinadas reservas jurídicas y fácticas. En concreto, cuando la reserva de lo políticamente adecuado u 
oportuno restringe las prestaciones que no son reconocidas por el Poder Público, o cuando por la reserva de lo financieramente posible restringe el amparo de determinada posición jurídica, por cuanto la distribución realizada en el escenario político, técnicamente no fue adecuada para garantizar el derecho fundamental como un todo; en ese caso, suponiéndose que no se presenta una colisión de derechos fundamentales, para que dependiendo la situación jurídica y fáctica de lugar a su exigibilidad, el ciudadano que acceda a la justicia de forma individual solicita el amparo de su derecho, ¿cuál debe ser la respuesta del Estado?

De cualquier forma, no se puede justificar la omisión administrativa o legislativa para negar una posición sujeta a reserva de lo fáctico y jurídicamente posible, la falla consiste en una reforma estructural que requiere el Estado. Por ejemplo, entiéndase como la crisis de la salud en Colombia requiere de una reforma en las bases que fueron el piso para el diseño, planeación y ejecución de las políticas públicas en materia de salud. En concreto, la crisis financiera que atraviesa el sistema de salud corresponde con el papel atribuido a la administración de la salud después de la ley 100 de 1993, que desencadenó una urgencia económica en el reconocimiento de prestaciones entre prestadores, empresas administradoras y Estado. El diseño de la ley generó una apertura y una centralización del sistema en el sector privado, que desembocó en altos niveles de corrupción del sistema y en una traba constante a los servicios que debían ser prestados a la sociedad 50 .

Por su parte, mientras las reformas estructurales al Estado toman un tiempo considerable, su colisión frente a la inmediatez y urgencia que muchas veces acompaña la garantía de un derecho fundamental social, debe ser ponderado con diferentes fórmulas o medidas a corto o a largo plazo. Entre las medidas a corto plazo, la posibilidad de adoptar una decisión judicial más técnica genera cierta provocación y podría presentarse como una solución temporal. Esto es, todo asunto que deba tomar la justicia constitucional mientras no haya una reforma sobre un asunto en particular, que sea respetuosa las competencias constitucionalmente atribuidas y el rol constitucional de los otros poderes, podría partir de una evaluación de impacto decisional en materia constitucional tanto anterior como posterior.

A partir de esta evaluación, la justicia ordenaría dentro de los límites establecidos, que tanto el legislador a través de una comisión accidental de asuntos constitucionales, como la autoridad

50 Sobre el asunto resulta interesante el análisis de Bardey (2020); Zapata (2017), pp. 169-189. Con una visión más económica Gaviria y Medina (2006), pp. 29-72. Para entender el caso brasileiro véase Bitencourt y Reck (2017), pp. 121-147; Pivetta (2010), pp. 209-230. 
administrativa competente, justifiquen de manera técnica y científica la razón por la cual no ha sido posible el amparo de ese derecho dentro de sus competencias. Y así, para no correr con los riesgos que trae el escenario político, el Tribunal podría diseñar de manera similar a como operan los conjueces cuando existe una recusación, una lista de científicos y académicos multidisciplinares, que después de una elección aleatoria, puedan controvertir la primera evaluación de impacto, así, con dos posibilidades y valoraciones técnicas, puede operar de forma más adecuada la decisión del juez constitucional.

Por su parte, las medidas a largo plazo parten de la necesidad de una reforma estructural, no en tanto, estas medidas podrían estar acompañadas de un diálogo institucional entre poderes públicos, ${ }^{51}$ la efectividad o no de este diálogo siempre debe considerar la importancia de los límites a la actuación de los tribunales constitucionales en un esquema de equilibrio de poderes, estos límites, de una u otra manera estarán guiados por la legalidad, en cuanto la sujeción de su decisión a las funciones atribuidas por la Constitución y por la ley, la racionalidad producto de una práctica lógica y técnica, la armonía institucional, que de algún modo justifica el diálogo institucional, la prevalencia de la independencia como una garantía ciudadana y la legitimidad.

En cuarto lugar, referirse al "activismo judicial" como un riesgo, atribuye un adjetivo negativo a determinadas formas en que actúan los tribunales constitucionales. No obstante, esa connotación de riesgo parece insuficiente en un escenario en que el entendimiento del “activismo judicial” parte de mitos, defensas y rechazos en torno a su definición. ${ }^{52}$ Parte de esta confusión se debe al entendimiento histórico del activismo, a los períodos de actuación de la Corte Suprema de los Estados Unidos, desde la decisión Brown vs. Board of Education of Topeka con el Tribunal de Warren (1953-1969) hasta la decisión Row vs. Wade con el Tribunal de Warren Burguer (1969-1986), periodos tales, dieron a entender que los americanos querían desarrollar el dogma constitucional de Montesquieu con todo y consecuencias, que de algún modo, conllevó a la alteración del equilibrio en favor del poder judicial correspondiente con una supremacía política en desmedro de las competencias legislativa ${ }^{53}$.

Además de lo anterior, la idea de activismo, la supremacía de los jueces o la ubicuidad de los mismos, correspondería con el desarrollo de un proyecto político que intentó legitimar el imperio de la libertad de una minoría económicamente capaz de dominar una mayoría

\footnotetext{
${ }^{51}$ Sobre el asunto véase: Gargarella (2013); Pou (2019). Así también Ávila y Melo (2018), pp. 83-108.

52 Gallo y Sanabria (2020).

${ }^{53}$ Lambert (2010), p. 57.
} 
históricamente indefensa. Esto último tiene una relación estrecha con el entendimiento de la propiedad, la libertad y la seguridad de las élites coloniales durante las guerras revolucionarias que antecedieron la Constitución americana ${ }^{54}$. Frente a esas inestabilidades, acompañadas de un constitucionalismo liberal identificado en una irracionalidad política y estratégica de los federalistas de élite, que acrecentó la denominación racial y de clase, se fortaleció la forma a través de las cuales se daban atribuciones a un poder constituido para transformar los intereses particulares en un asunto estructural. El nuevo constitucionalismo llegó así, como una herramienta o un seguro frente a un ambiente político inestable. Al tiempo que el "activismo judicial" históricamente se desarrolló como un asunto de clase, la revisión constitucional correspondió con una especie de certeza. ${ }^{55}$

La traspolación de este fenómeno en la justicia constitucional en Brasil y en Colombia a partir de la expedición de sus constituciones actuales, adoptó un entendimiento aparentemente dispar. En ambos contextos, se caracterizó por la heterogeneidad al sistematizar el universo de cortes, tribunales y jueces constitucionales, la apertura al ciudadano y el riesgo del hiperpresidencialismo conjugado con una exuberante actuación judicial constitucional ${ }^{56}$. A su vez, este fenómeno encontró justificación normativa en el tratamiento otorgado por la Constitución de 1988 en Brasil y de 1991 en Colombia al Supremo Tribunal Federal y a la Corte Constitucional, como las guardianas de la integridad y la supremacía de la Constitución para el caso colombiano, o la competencia de la protección de la Constitución para el caso del Supremo Tribunal Federal en Brasil.

Aunado a lo anterior, ambos ordenamientos jurídicos consagraron un amplio catálogo de derechos fundamentales y una destacable caja de herramientas procesales para la garantía de los derechos fundamentales. Adoptaron también un control mixto de constitucionalidad y diversos entendimientos alrededor de la acción pública de constitucionalidad. Con todo, la generalidad constitucional desembocó en una función de la Corte y del Tribunal más allá de sus límites, que siempre amparados bajo la guarda constitucional, no han considerado su evidente injerencia en el poder legislativo o en el ejecutivo. Así pues, entender cuando existe activismo o no, es una idea que no presenta una simple respuesta, no se pretenden generar posiciones absolutas alrededor del activismo.

\footnotetext{
${ }^{54}$ Gill y Cutler (2014), pp. 77-79.

${ }^{55}$ Hirschl (2014), p. 98.

${ }^{56}$ Roa (2019), pp. 450-481.
} 
De manera preliminar podría decirse que, el argumento amparado en la dificultad contramayoritaria, encaminado a reconocer derechos fundamentales, a proteger valores y principios que le deben ser atribuidos a ciertos grupos de la población que históricamente han sido marginados no puede ser catalogada como una decisión activista negativa. La lucha y la conquista de los derechos de las personas LGBTI+, y de la eutanasia, por tomar dos ejemplos, son manifestaciones de la libre determinación de la sociedad y de su reconocimiento igualitario que corresponden a un desarrollo histórico, por lo menos en la sociedad occidental que comparte Brasil y Colombia, su no reconocimiento implicaría desconocer un proceso histórico ya identificable en otros países con elementos sociales comunes.

Otro asunto corresponde con la injerencia de funciones sobre los otros poderes y con el populismo ideológico de estos tribunales ${ }^{57}$, sobre todo este último, sustentado en discursos moralistas que han intentado desdibujar la compatibilidad que debe existir entre la justicia constitucional y la Constitución, en estos casos, acompañados de las razones presentadas en el escrito podría hablarse de un activismo judicial de talante negativa que genera inestabilidad para la democracia.

Las consideraciones finales a las ideas propuestas en este escrito, en realidad se convierten en un punto para el inicio de críticas, reflexiones y proposiciones a la hipótesis defendida. Esta es, la concesión de prestaciones basadas en la titularidad de los derechos sociales en la jurisprudencia de la Corte Constitucional viene siendo errónea tanto por la jurisprudencia como por la doctrina, por cuanto alega prevalentemente una dimensión subjetiva de los derechos sociales, apartándose de la real existencia de una doble dimensión, una doble titularidad (individual y transindividual) y una multifuncionalidad de los mismos.

Esas razones encuentran fundamento en soportes de diferente naturaleza, desde argumentos económicos hasta semánticos o terminológicos. Básicamente consisten en que la idea de derecho fundamental ha oscilado entre lo que se trata como derechos subjetivos de aplicación inmediata, la inalienabilidad y la esencialidad del derecho a la persona, la exclusiva e histórica atribución dada a los derechos sociales, cuyos vestigios aún subsisten en el presente, la vaguedad conceptual que presenta la Corte Constitucional entre la afectación del derecho de todos y la garantía de prerrogativas individuales y, las barreras burocráticas de cualquier índole que se anteponen a la tutela administrativa efectiva de los derechos.

${ }^{57}$ Sobre el asunto véase Salgado (2018), pp. 193-217. 
Por su parte, un diálogo que atienda estas razones, encuentra propuesta dialógica y comparada en las críticas realizadas por la doctrina a las decisiones del Supremo Tribunal Federal de Brasil, las cuales comparten elementos tanto social como históricamente comunes. Así, las críticas consisten básicamente en que los derechos fundamentales sociales considerados integralmente o como un todo presentan una faceta individual y una transindividual dependiendo de la pretensión en análisis. Asimismo, atendiendo a su multidimensionalidad, los derechos fundamentales sociales son más que un mero derecho subjetivo. Finalmente, el entendimiento de la transmutación hacia una garantía subjetiva de los derechos fundamentales sociales corresponde con una resubjetivización de la dimensión objetiva que abre paso a una dimensión subjetiva transindividual.

Con todo, los riesgos identificados a partir de las críticas expuestas evidencian que, el análisis actual de la concesión de prestaciones individuales presenta varias inconsistencias que se pueden percibir en las críticas realizadas a las decisiones del Supremo Tribunal Federal de Brasil, fundadas en la teoría de los derechos fundamentales sociales, su multifuncionalidad y su doble titularidad. Asimismo, esas inconsistencias representan una característica "activista" de ambos tribunales, por lo que se requiere evaluar la forma interpretativa e identificar algunos límites que permitan garantizar la legalidad, la armonía institucional fundada, de forma posible, en el diálogo institucional, la independencia judicial y la legitimidad institucional. El estudio es preliminar, el debate toma apertura, las ideas propuestas pueden ser una provocación, resultados más definitivos serán fruto de investigaciones posteriores.

\section{Bibliografía citada}

Alexy, Robert (2014): Teoria dos direitos fundamentais (São Paulo, Malheiros).

Avila, Ana Paula Oliveira; Melo, Karen Cristina Correa de (2018): "Separação de poderes e diálogos institucionais nos litígios envolvendo o direito à saúde", en Revista de Investigações Constitucionais (Vol. 5, №1), pp. 83-108.

Arango, Rodolfo (1997): “Los derechos sociales fundamentales como derechos subjetivos”, en Pensamiento Jurídico (8), pp. 70.

(2001): "La justiciabilidad de los Derechos sociales fundamentales", en Revista de Derecho Público (año 12), pp. 185-212. 
Bardey, David (2020): "El sistema de salud colombiano: ¿bueno o malo? Universidad de los Andes". [Disponible en: https://bit.ly/3n64QxB]. [Fecha de consulta: 15 Júlio 2020].

Bitencourt, Caroline Müller (2013): Controle jurisdicional de políticas públicas (Porto Alegre, Núria Fabris Editora).

(2015): “Sobre o possível controle judicial de políticas públicas: um olhar a partir do campo de conformação do legislador e do administrador" en Revista Eurolatinoamericana de Derecho Administrativo (Vol. 2, №2), pp. 143-166.

Bitencourt, Caroline Müller; Reck, Janriê Rodrigues (2017): “Democracia deliberativa, teoria da decisão e suas repercussões no controle social das despesas em saúde" en Revista de Direito Econômico e Socioambiental (Vol. 8, №1), pp. 121-147.

Bitencourt Neto, Eurico (2010): O direito ao mínimo para uma existência digna (Porto Alegre, Livraria do Advogado).

Botero, Catalina (2009): La acción de Tutela en el Ordenamiento Constitucional Colombiano (Bogotá D.C, Escuela Judicial “Rodrigo Lara Bonilla”).

CNMH. Centro de Memoria Histórica (2018): Justicia: Balance de la contribución del CNMH al esclarecimiento histórico (Bogotá D.C, CNMH).

Corporación Excelencia de la Justicia (2019): “Casi 7 de cada 10 órdenes de tutela se incumplieron en 2019". [Disponible en: https://bit.ly/31SErLv]. [Fecha de consulta: 15 de julio de 2020].

Ferreira, Siddharta Legale; Fernandes, Eric Baracho Dore (2013): “O STF nas “Cortes” Victor Nunes Leal, Moreira Alves e Gilmar Mendes” en Revista Direito GV, (Vol. 9, №1), pp. 23-45. [Disponible en: https://bit.ly/3wDSAHu]. [Fecha de consulta: 28 de julio 2020].

Gabardo, Emerson (2017): “O princípio da supremacia do interesse público sobre o interesse privado como fundamento do Direito Administrativo Social” en Revista de Investigações Constitucionais (Vol. 4, №2), pp. 95-130. 
Galindo, Hector; Restrepo, Jorge; Sanchez, Fabio (2009): “Conflicto y pobreza en Colombia: un enfoque institucionalista", en; Restrepo, Jorge; Aponte, David (ed.) Guerras y violencia en Colombia. Herramientas e interpretaciones (Bogotá D.C, Pontificia Universidad Javeriana).

Gallo, William; Sanabria, Alejandro (2020): “Aproximación a los límites del activismo judicial de los jueces constitucionales: el caso de la Corte Constitucional de Colombia y del Supremo Tribunal Federal de Brasil”, en Anuario Iberoamericano de Derecho Constitucional (Bogotá D.C, Ed. Konrad Adenauder Stiftung)

García, Mauricio; Uprimny, Rodrigo (2002): “Tribunal Constitucional e emancipaçã social na Colombia", en Santos, Boaventura de Sousa (ed.) Democratizar a democracia. Os caminhos da democracia participativa (Rio de Janeiro, Civilización brasileira), pp. 298-339. Disponible en: [https://bit.ly/3c51Nzs]. [Fecha de consulta: 1 de julio 2020].

Gargarella, Roberto (2013): "El nuevo constitucionalismo dialógico frente al sistema de los frenos y contrapesos", en Revista Argentina de Teoría Jurídica (Versión digital) (Vol. 14, №2) [Disponible en: https://bit.ly/3wEFs5i]. [Fecha de consulta: 28 julio 2020].

Gaviria, Alejandro; Medina, Carlos (2006): “Assessing Health Reform in Colombia: From Theory to Practice [with Comments]" en Brookings Institution Press, (Vol. 7, №1), pp. 29-72. [Disponible en: https://bit.ly/3C9rOrP]. [Fecha de consulta: 16 julio 2020].

Gutiérrez, Andrés (2010): “Tendencia actual de amparo en materia de derechos económicos, sociales y culturales en la jurisprudencia de la Corte Constitucional" en Revista Derecho del Estado (№ 24), pp. 81-103, [Disponible en: https://bit.ly/3F5j87J]. [ Fecha de consulta: 17 de julio de 2020].

Gill, Stephen. Cutlher, Claire (2014): “Genealogy, origins and world order" en New Constitutionalism and World Order (Cambridge: Cambridge University Press).

Hachem, Daniel Wunder (2013): "A dupla titularidade (individual e transindividual) dos direitos fundamentais econômicos, sociais, culturais e ambientais", en Revista Direitos Fundamentais \& Democracia (UniBrasil) (Vol. 14, №14.1), pp. 618-688. 
(2013): “A maximização dos direitos fundamentais econômicos e sociais pela via administrativa e a promoção do desenvolvimento", en Revista Direitos Fundamentais \& Democracia (UniBrasil) (Vol. 13, №13), pp. 340-399.

(2013): “A noção constitucional de desenvolvimento para além do viés econômico: reflexos sobre algumas tendências do Direito Público brasileiro". En A\&C-Revista de Direito Administrativo \& Constitucional (13, №53), pp. 133-168.

(2014): “Mínimo existencial y derechos económicos y sociales: distinciones y puntos de contacto a la luz de la doctrina y jurisprudencia brasileñas", en Revista Eurolatinoamericana de Derecho Administrativo (Vol. 1, №1), pp. 93-138.

(2019): "São os direitos sociais “direitos públicos subjetivos"? Mitos e confusões na teoria dos direitos fundamentais", en Revista de Estudos Constitucionais, Hermenêutica e Teoria do Direito (RECHTD) (Vol. 11, №3), pp. 404-436.

Hirschl, Ran (2014): “The origins of the new constitutionalism: lessons from the 'old' constitutionalism" en Gill, Stephen; Cutler, Claire (ed). New Constitutionalism and World Order (Cambridge, Cambridge University Press), pp. 95-108.

Kalmanovitz, Salomón (2000): “El modelo anti-liberal colombiano”. [Disponible en: https://bit.ly/2YCBUDX]. [Fecha de consulta: 15 junio 2020].

Lambert, Eduard (2010): El gobierno de los jueces y la lucha contra la legislación social en los Estados Unidos. La experiencia americana del control judicial de la constitucionalidad de las leyes (Madrid, Editorial Tecnos).

Novais, Jorge Reis (2003): As restrições aos direitos fundamentais não expressamente autorizadas pela Constituição (Coimbra, Coimbra Editora).

(2010): Direitos sociais: teoria jurídica dos direitos sociais enquanto direitos fundamentais (Coimbra, Coimbra Editora).

Perry, Guillermo (2019): Decidí contarlo. Conversaciones sobre cincuenta años de economía y política en Colombia (Bogotá D.C, Editorial Debate). 
Pivetta, Saulo Lindorfer (2010): "Políticas públicas e a construção do conteúdo material do direito à saúde: desafio à Administração Pública brasileira", en $A \& C$ - Revista de Direito Administrativo \& Constitucional (año 10, №41), pp. 209-230.

Pou Giménez, Francisca (2019): “Las cortes latinoamericanas en un contexto de democracias dislocadas: un análisis desde el optimismo estratégico", en Niembro, Roberto; Verdugo, Sergio (coord.). La Justicia Constitucional en tiempos de cambio (Ciudad de México, Suprema Corte de Justicia de la Nación).

Roa, Jorge Ernesto (2019): Control de constitucionalidad deliberativo: El ciudadano ante la justicia constitucional, la acción pública de inconstitucionalidad y la legitimidad democrática del control judicial al legislador (Bogotá D.C, Universidad Externado de Colombia \& Centro de Estudios Constitucionales y Políticos de Madrid).

Rubio, Mauricio (2011): La Catedral y el Bazar: Reflexiones profanas sobre la justicia, (Bogotá, Universidad Externado de Colombia), pp. 260-343. [Disponible en: https://bit.ly/3c0MVlB]. [Fecha de consulta: 15 junio de 2020].

Saffon, Maria Paula; García-Villegas, Mauricio (2019): “Derechos sociales y activismo judicial: la dimensión fáctica del activismo judicial en derechos sociales en Colombia", en Estudios Socio-Jurídicos (Vol. 13, №1), pp. 75-107, [Disponible en: https://bit.ly/3ks3Tol]. [Fecha de consulta: 15 de julio 2019].

Salgado, Eneida Desiree (2018): "Populismo judicial, moralismo e o desprezo à Constituição: a democracia entre velhos e novos inimigos" en Revista Brasileira de Estudos Políticos (Vol. 117), pp. 193-217.

Sarlet, Ingo Wolfgang; Zockun, Carolina Zancaner (2016): “Notas sobre o mínimo existencial e sua interpretação pelo STF no âmbito do controle judicial das políticas públicas com base nos direitos sociais", en Revista de Investigações Constitucionais (Vol. 3, №2), pp. 115-141.

Sgarbossa, Luís Fernando (2010): Critica à teoria dos custos dos direitos: Reserva do possível (Porto Alegre, Sergio Antônio Fabris Editor). 
Soares, Hector Cury (2011): “O controle de constitucionalidade das políticas públicas no Brasil e a importação de modelos de controle de constitucionalidade pela Constituição de 1988", en Revista de Direito Econômico e Socioambiental (Vol. 2, №1), pp. 121-150.

Zapata, José Gabriel (2017): “Las ideologías políticas de la salud: legitimidad y permanencia de las desigualdades sociales y la exclusión en salud", en Dilemas en salud: Investigación en diálogos con las Ciencias Sociales y Humanas (Bogotá D.C, Universidad Externado de Colombia).

\section{Jurisprudencia citada}

Corte Constitucional de Colombia: Sentencia de tutela nº570, 1992.

Corte Constitucional de Colombia: Sentencia de constitucionalidad C-179, 1994.

Corte Constitucional de Colombia: Sentencia de tutela T-290, 1994.

Corte Constitucional de Colombia: Sentencia de constitucionalidad C-179, 13 de abril de 1994 .

Corte Constitucional de Colombia: Sentencia de tutela T-205, 1997.

Corte Constitucional de Colombia: Sentencia de unificación SU-111, 1997.

Corte Constitucional de Colombia: sentencia de constitucionalidad C-251,1997.

Corte Constitucional de Colombia: sentencia de constitucionalidad C-177, 1998.

Corte Constitucional de Colombia: Sentencia de Tutela T-662, 2006.

Corte constitucional de Colombia: Sentencia de Tutela T-016, 2007.

Corte Constitucional de Colombia: Sentencia de Tutela T-406, 2007.

Corte Constitucional de Colombia: Sentencia de Tutela T-760, 2008.

Corte Constitucional de Colombia: Sentencia de tutela T-880, 2009.

Corte Constitucional de Colombia: Sentencia de tutela T-717, 2012. 
Corte Constitucional de Colombia: Sentencia de tutela T-716, 2017.

Corte Constitucional de Colombia: Sentencia de unificación SU-124, 2018.

Corte Constitucional de Colombia: Sentencia de Tutela T-479, 2019.

Corte Constitucional de Colombia: Sentencia de Tutela T-209, 2019.

Corte Constitucional de Colombia: Sentencia de tutela T-409, 2019.

Consejo de Estado: Sentencia de la sala de consulta y servicio civil rad. 2177, 2013. 